\title{
GREEN BONDS REPRESENTING GREEN FINANCE IN EUROPE - BASIC CHARACTERISTICS
}

\author{
Simon C. Stölzle ${ }^{1}$ \\ Dominika P. Galkiewicz ${ }^{2}$
}

DOI: https://doi.org/10.31410/LIMEN.S.P.2020.27

\begin{abstract}
This study examines whether there is a negative green bond premium for investors in the secondary European market. To answer this question, the matched pairs method is applied, where the daily $i$-spreads of green bonds and the interpolated daily $i$-spreads of similar non-green bonds are compared. The bond sample contains 37 bond couples issued by corporations, financial institutions and governments between November 2019 and April 2020. The findings suggest that there is an average statistically significant negative very small green bond premium. The negative premium could be explained by investors' preferences for green financial instruments leading to excess demand. The negative green bond premium may also be a compensation for the issuer's external costs or reflect the internalization of environmental externalities. Further evidence shows that the negative green bond premium varies across industries and is not higher for lower rated investment grade bonds.
\end{abstract}

Keywords: Green, Bond, Green finance, Premium, Europe.

\section{INTRODUCTION}

7 he fight against global warming and climate change is one of the greatest challenges humankind is facing in this century. The frequency of climate disasters and structural inequalities in the world are increased. To counteract climate change, the Paris Agreement was signed at the $21^{\text {st }}$ Conference of Parties (COP21). Its main goal is to keep the global temperature well below $2{ }^{\circ} \mathrm{C}$ above pre-industrial levels. Thus, radical changes in energy, transport, construction and water infrastructure are needed, as these industries are responsible for over $60 \%$ of the greenhouse gases produced (OECD (2018)). The Organisation for Economic Co-operation and Development (OECD) estimates that investments in the region of USD \$6.9 trillion will be needed for the global infrastructure to meet the sustainable development goals of the Paris Agreement. Government budgets are unable to produce or make available such sums on their own. Therefore, private investments are required. One option for funding such infrastructural changes is 'green finance' and herein green bonds (OECD (2018)).

Green bonds are playing an increasingly important role in the financial market and are actively contributing to the fight against climate change, which is of great interest to investors, bond issuers and policymakers. For these reasons, it is relevant to understand the nature of green bonds and to contrast them to conventional bonds, especially in terms of yield performance. The underlying research question of this study is: How do green bonds differ from conventional

$1 \quad$ University of Applied Sciences Kufstein, Finance, Accounting \& Auditing through the "Crowdfunding Monitor" project and a bond trader at MGW Geld- und Wertpapiervermittlung, Raiffeisenallee 16, 82041 Oberhaching, Germany

2 University of Applied Sciences Kufstein Tirol, Finance, Accounting \& Auditing, Andreas Hofer-Str. 7 , 6330 Kufstein, Austria 
bonds? Previous green bond studies have shown that there is mostly a negative green bond premium, thus, investors forgive some returns if investing green. Preclaw and Bakashi (2015) and Ehlers and Packer (2017) suggest that there is a green bond premium of -17 basis points (bps) and -18 bps p.a., respectively. Zerbib (2019) documents a green bond premium of -2 bps p.a., whereas Hachenberg and Schiereck (2018) do not find a significant green bond premium. In contrast, Karpf and Mandel (2018) and Bachelet et al. (2019) determine a positive green bond premium ranging from 2.06 to $7.80 \mathrm{bps}$ p.a. It can also be seen in Karp and Mandel (2018) that the green bond premium is switching from positive to negative over time. Thus, this study aims to investigate the differences between green and non-green bonds based on the most recent European data incorporating the effects of the beginning of the Corona-Pandemic. This is the first green bond study of its kind focusing on the European area, i.e. on green bond issuers incorporated in Europe. The green bonds are denominated in Euros and placed in the secondary market between November 1, 2019, and April 30, 2020.

Overall, the evidence confirms that green bonds are issued for different, in particular ethical climate change and wealth of nations oriented, reasons. Furthermore, a small negative green bond premium is observable. These results are highly relevant for policymakers, green issuers and investors and further contribute to the debate on sustainable development.

In the following, Section 2 provides a brief background on green finance and the performance of green bonds. Next, in section 3 data and methodology are described, before the results of testing the characteristics of green versus non-green bonds are discussed in section 4 . Section 5 concludes the paper.

\section{BACKGROUND ON GREEN FINANCE AND GREEN BONDS}

There is still no unique or commonly accepted definition of green finance. Definitions vary regarding scope and transparency (Migliorelli and Dessertine (2020)), but one of these definitions come from the G20 Green Finance Study Group (2016): "Financing of investments that provide environmental benefits in the broader context of environmentally sustainable development (...). Beyond the financing of green investments, green finance also involves efforts to internalize environmental externalities and adjust risk perceptions in order to boost environmentally friendly investments and reduce environmentally harmful ones (...)." "3 A closer look on various definitions reveals a common ground, which is that "green finance provides a bridge between global environmental priorities and the financial system."4

Green finance is often described as "the green pillar of sustainable finance." The main distinction between green and sustainable finance is that sustainable finance integrates all Environmental, Social and Governance (ESG) dimensions when it comes to evaluation. As the abbreviation ESG implies, three dimensions are connected to firms' environmental, social and governance operations. For instance, the environmental dimensions focus on how companies respond to problems such as climate change, pollution, waste and the allocation of scarce resources (Dorfleitner et al. (2015)). Polbennikova et al. (2016) analyse the effect of ESG ratings on bonds and find that bonds with better ESG ratings are rewarded with tighter spreads and better performance. The 193 countries that comprise the UN General Assembly agreed on the 2030 Agenda for Sustainable Development. This declaration contains 17 sustainable development goals (SDGs). Moreover, sustainable finance aims at the fulfillment of all SDGs,

G20 Green Study Group (2016), p. 3.

Green Finance Initiative (2016), p. 9.

Green Finance Initiative (2016), p. 9. 
whereas green finance only addresses the environment-related SDGs (Kahlenborn et al. (2017)). Nine out of the 17 goals are linked to environmental protection. This is significant because green finance can support the achievement of more than half of the SDGs.

Green finance offers a wide range of products and services. However, green bonds are the main representatives and serve as a foundation for many other products and services. In 2019, the global green bond and green loan issuances achieved a new global record of $\$ 257.7$ billion, of which $\$ 10$ billion were green loans (4\%). This was an increase of 51\% from the previous year of $\$ 170.6$ billion. A green bond is a fixed income product that allows investors to support the environment and help institutions and countries achieving their climate change adaptation and mitigation goals. There are also climate bonds in the green bond market, but they are not specifically labelled as such, hence, they are included under the label of green bonds (Bachelet, Becchetti and Manfredonia (2019)). In 2007, the European Investment Bank (EIB) launched the first green bond (the Climate Awareness Bond) with proceeds dedicated to energy efficiency and renewable energy projects. In the next year, the World Bank followed with a similar issuance (Migliorelli and Dessertine (2020)). From this point on, in most cases the issuers were multilateral development banks (MDBs) and sovereign supranational agencies (SSAs). After the launch of the green bond principles, new diverse issuers joined the green bond market including corporations, governments and banks. Since then, the green bond market and annual green bond issuances have gathered more attention and have grown rapidly year by year (Ketterer et al. (2019)).

The Climate Bonds Initiative reports 1,788 green bonds outstanding from 496 different issuers. In 2019, for the first time non-financial corporations held the lion's share of the green bond market followed by financial corporations (CBI (2020)). The most volume is driven by the European market, which represented $45 \%$ of the global issuance, while the second and third positions are held by the Asia-Pacific and North American markets, at 25\% and 23\%, respectively. One may get the impression that the green bond market is extremely large, but it still represents less than $1 \%$ of the global bond market (Ketterer et al. (2019)).

The aforementioned development was supported by establishing a framework with important criteria and standards for the green label (Preclaw and Bakshi (2015)). The most established and accepted guidelines are the Green Bond Principles (GBP) created in 2014 by the International Capital Market Association (ICMA). The guidelines outline four key aspects of the life of a green bond: the use of proceeds, the process for project evaluation and selection, the management of proceeds and reporting (Preclaw and Bakshi (2015)). As adherence to the GBP is voluntary, some market participants are concerned about potential problems that may arise when there are no strict rules or standards. External reviews are particularly important when it comes to labelling a green bond. To counteract asymmetric information between investors and issuers, a number of organisations focus on promoting transparency with regard to green bonds and their use of green bond proceeds. These external reviewers verify the performance of environmental projects and their effects. Roughly $60 \%$ of green bonds are additionally certified by an external party (Boulle et al. (2016)). The types of review (i.e. second-party opinion, third-party assurance report or green bond rating) can be performed either pre- or post-issuance. One example of a green bond-rating agency is S\&P, which divides the rating into five classes: GB5 (poor), GB4 (fair), GB3 (good), GB2 (very good) and GB1 (excellent). The alignment with the GBP is particularly important in external reviews (Migliorelli and Dessertine (2020)). The transaction cost for a single issuance varies and depends on the type of green bond, the particular market, the issue size, the issuer and the frequency with which green bonds are issued. In 2016, (Ceci (2016)) estimated the external 
costs for a 500 million (USD) green bond to range between 0.3 to $0.6 \mathrm{bps}$. These costs need to be taken into consideration by the issuers.

Investors generally focus on the trade-off between risk and return. Previous literature shows that green investors most often face a negative green bond premium (e.g. Preclaw and Bakashi (2015), Ehlers and Packers (2017) and Zerbib (2019)) and seldom a positive green bond premium (Karp and Mandel (2017) and Bachelet et al. (2019)). The occurrence of a negative green bond premium, meaning that investors forgive some yield for investing green, can be explained by excessive demand for green bonds reflected in oversubscription. Another reason could be the preference of investors and their willingness to accept lower yields to acquire indirect gains. Finally, it can also be viewed as compensation for the external costs or the internalisation of environmental externalities (Preclaw and Bakshi (2015)).

In Europe, the European Commission is attempting to structure a common foundation for green finance (Boracheva and Smorodinov (2017)). Most issuers realise that there will be at least reputational gains and CSR recognition. Examples of advantages could be lowered costs of green labelling or/and faster placements in a portfolio. To have a major impact on the environment, green finance needs to further develop from a niche to mainstream financing mode. This poses a major challenge to policymakers, as the burden of implementation would largely fall on them (Berensmann and Lindenberg (2019)). Another challenge is the international political commitment to fight climate change and support the environment. In addition, there are challenges specific to the green bond market. Problems arise due to a lack of standardized green bond ratings, indices and listings, domestic green investors, local green bond guidelines, and the lack of awareness of international practices and the advantages of green bonds. The cost of issuing a green bond is, for small issuers, a barrier and reduces the supply of green bonds available on the market. Other difficulties arise when international investors wish to join local markets due to the differences in green bond definitions and issues such as capital controls. The development of green finance and the green bond market has great potential, but there is still much to be done (Kahlenborn et al. (2017)).

\section{DATA AND METHODOLOGY}

In order to determine, whether there is any positive or negative green bond premium, 37 green bonds and 74 non-green bonds were collected from November 1, 2019, to April 30, 2020. The daily spreads of the non-green bonds were interpolated (i-spreads) to create a synthetic bond that is most equivalent to the respective green bond. The $i$-spreads are nominated in bps over a so-called 'risk-free benchmark'. For the purposes of the analysis, the matched pair method was applied. The final sample contains 37 green and 37 non-green bonds (bond couples) issued by corporations, financial institutions and governments required to have ESG ratings from RobecoSAM or Sustainalytics. The sample shows that 21 issuers have an ESG rating from at least one of the two rating agencies. The data stems from Bloomberg.

Table 1 shows the results of pre-tests consisting of an analysis of Pearson Rank Sum Correlations of daily i-spreads used in the study and of Wilcoxon Signed-Rank Tests applied to them for each rating and industry category, respectively. The t-test analyses whether a negative green bond premium can be observed 
Table 1. Wilcoxon signed-rank test and t-test for rating groups and industries

\begin{tabular}{llllll}
\hline \hline & Total Sample & AAA & AA & A & BBB \\
\hline N daily i-spreads & 9,250 & 2,000 & 1,750 & 3,250 & 2,250 \\
$p_{\text {value signed rank test }}$ & $0.000^{* * *}$ & $0.000^{* * *}$ & $0.006^{* * *}$ & $0.000^{* * *}$ & $0.000^{* * *}$ \\
$p_{\text {value one-tailed t-test }}$ & $0.000^{* * *}$ & $0.000^{* * *}$ & $0.000^{* * *}$ & $0.000^{* * *}$ & $0.000^{* * *}$ \\
$r_{\text {green, non-green }}$ & 0.995 & 0.988 & 0.9956 & 0.994 & 0.992 \\
\hline & Total Sample & Government-related & Financials & Corporates \\
\hline N daily i-spreads & 9,250 & 1,000 & & 4,000 & 4,250 \\
$p_{\text {value signed rank test }}$ & $0.000^{* * *}$ & $0.000^{* * *}$ & & $0.000^{* * *}$ & $0.000^{* * *}$ \\
$p_{\text {value one-tailed t-test }}$ & $0.000^{* * *}$ & $0.000^{* * *}$ & & $0.000^{* * *}$ & $0.000^{* * *}$ \\
$r_{\text {green, non-green }}$ & 0.995 & 0.985 & & 0.997 & 0.991 \\
\hline
\end{tabular}

Significance levels at the $1 \%, 5 \%, 10 \%$ are indicated as $* * *, * * *$

In sum, the $p$-values of both statistical hypothesis tests are highly statistically significant among all rating classes and industries confirming the existence of a negative green bond premium. Furthermore, Table 1 presents the correlation coefficient between the daily i-spreads of the green bonds and the interpolated daily i-spreads of the non-green bonds. The two i-spreads are highly positively correlated for the total sample (as can also be seen in Figure 1 and 2), which confirms that the interpolation underlying the matched pairs method was accurately executed.

A negative green bond premium can have many possible causes. One is the strong demand for green bonds, which often exceeds the supply and becomes visible through oversubscription (Preclaw and Bakashi (2015) and Ehlers and Packers (2017)). Alternatively, investor might prefer to trade financial gains for non-financial gains (e.g., reputation or a good feeling as a result of supporting sustainability). For the first five years of their analysis of the US municipal bond market, Karp and Mandel (2018) found a green bond premium of 7.8 bps p.a., which became a negative premium in the last two years. The initially positive green bond premium could be due to the fact that the green bond sample was not aligned with the GBP (i.e. many of the bonds were greenwashed instead of being truly green). The researchers stated that the change in the green bond premium could be traced back to the improvements in credit quality, financial performance and herding behaviour. This would suggest that a negative green bond premium is due to the issuer's high credit quality and financial performance. As mentioned in section 2, most green bond issuers have to bear the cost of external reviews and transaction costs. Therefore, they might cover these costs by paying lower interest rates to investors. ${ }^{6}$

\section{RESULTS}

Table 2 presents the means, medians, standard deviations, minimums, maximums and number of daily i-spreads for the fixed-rate green bonds expressed in basis points. The sample of the daily i-spreads is sorted by the four rating classes of investment grade bonds. The arithmetic mean of the daily $\mathrm{i}$-spreads of the green bonds increases as the rating gets lower. This is due to the increasing default risk premium investors demand for lower-rated bonds. There is a significant jump of more than 41 bps from AAA to AA followed by a moderate increase in each

6 As mentioned before, the negative green bond premium could also reflect the internalisation of environmental externalities such as mitigating climate risk (Preclaw and Bakshi (2015)). 
successive rating class. As can be seen, in the mean daily i-spread of AAA-rated bonds, the ispread can also be negative. This is a result of the most recent phenomenon of the decade: negative interest rates. The $-1.83 \mathrm{bps}$ can be interpreted as the investor having to pay a $0.018 \%$ yield to invest his or her money into these bonds. The reason is that $-0.018 \%$ of lost yield is still better than paying, for example, the current Euro-Bund-Future ${ }^{7}$ with over $-0.40 \%$ yield. The underlying assumption is that the investor wants to invest in a risk-free bond.

Table 2. Summary of the daily i-spreads of green bonds

\begin{tabular}{l|rrrrrc}
\hline \hline Rating & Mean & Median & SD & Min & Max & $n$ daily i-spreads \\
\hline AAA & -1.830 & -3.34 & 9.810 & -25.715 & 26.839 & 1000 \\
AA & 39.325 & 27.37 & 36.685 & -2.476 & 153.504 & 875 \\
A & 56.912 & 40.75 & 45.865 & 11.120 & 254.967 & 1625 \\
BBB & 82.588 & 82.58 & 65.478 & 23.423 & 373.340 & 1125 \\
\hline Total & 47.129 & 33.29 & 54.089 & -25.715 & 373.340 & 4625 \\
\hline \hline
\end{tabular}

Table 3 shows the means of the daily deltas between the daily i-spreads of the green bonds and the interpolated daily i-spreads of the non-green bonds. The bonds are evenly distributed among the rating classes. The tightest and widest daily means of the delta do not refer to tight and wide pricing in the market, but are equivalent to the minimum and maximum, respectively.

Table 3. Summary of the daily i-spread deltas of green and non-green bonds

\begin{tabular}{llllllll}
\hline \hline Rating & $n$ bonds & Tightest daily $i_{d}$ & Widest daily $i_{d}$ & Mean $i_{d}$ & Median $i_{d}$ & Mean $i_{g}$ & Mean $\mathrm{i}_{\mathrm{n}}$ \\
\hline AAA & 8 & -11.98 & 4.30 & -0.61 & -0.54 & -1.83 & -1.22 \\
AA & 7 & -10.78 & 10.87 & -0.53 & -0.07 & 39.32 & 39.85 \\
A & 13 & -15.01 & 20.99 & -0.80 & -0.88 & 56.91 & 57.72 \\
BBB & 9 & -64.47 & 11.75 & -1.69 & -1.52 & 82.58 & 84.28 \\
\hline Total & 37 & -64.47 & 20.99 & -0.93 & -0.61 & 47.12 & 48.05 \\
\hline \hline
\end{tabular}

The mean of $i_{d}$ indicates whether there is an economically negative green bond premium. As can be observed in all four rating classes, there is a small negative premium for green bonds. BBB-rated green bonds have, on average, the highest negative premium of 1.69 bps p.a., followed by A-rated bonds with a negative premium of 0.80 bps p.a. Due to their higher rating, the AA-rated bonds have a lower negative premium of $0.53 \mathrm{bps}$ p.a. Contrary to expectations, the AAA-rated green bonds have a green premium of -0.61 bps p.a., which is greater than that of the A-rated bonds. The total negative green bond premium equals $0.93 \mathrm{bps}$ p.a., which is in economic terms, very low. If investors chose a green bond over a non-green bond, they would only forgo $0.0093 \%$ in yield on an annual basis.

Figures 1 and 2 illustrate the progress of the daily i-spreads of the green bonds and the interpolated daily i-spreads of the non-green bonds for AAA and BBB rating classes from November 1, 2019, to April 30, 2020. The vertical axis represents the i-spreads, and the horizontal axis represents the time. As the figures indicate, the i-spreads of green and non-green bonds move in the same direction and stick close together. It can be seen from all two figures that there is a sharp increase in the daily i-spreads from March onwards. The reason for this is the effect of the global coronavirus pandemic. The unknown risk of the coronavirus crisis has

7 The Euro-Bund-Future is a fictitious German govt. bond with a coupon rate of $6 \%$ and a maturity of 10 years (Bösch (2020)). 
created uncertainty in the bond market, which resulted in a strong market response (Fleming and Remolona (1999)). Higher trading activity and increased sales of bonds caused the ispreads to rise. This triggered further sales because investors want to offload older bonds in anticipation of bonds with better yields. In addition, greater liquidity is needed due to the loss of revenue during the pandemic. Investors also demand higher interest rates due to the increased default risk that arises from the unknown economic consequences of the coronavirus crisis (Der Tagesspiegel (2020)).

Figure 1. Green vs. non-green bonds with AAA ratings

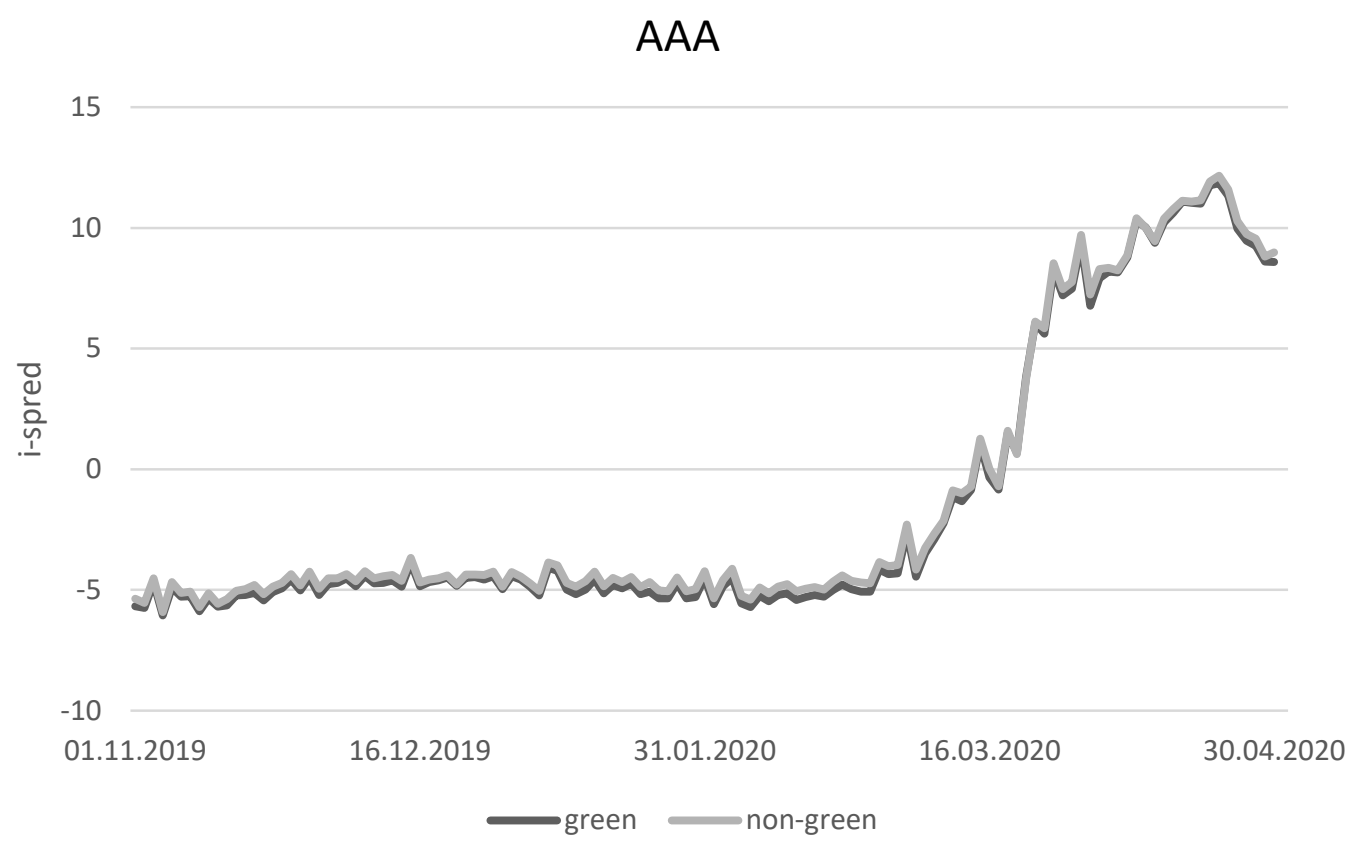

Figure 2. Green vs. non-green bonds with BBB ratings

\section{BBB}

250

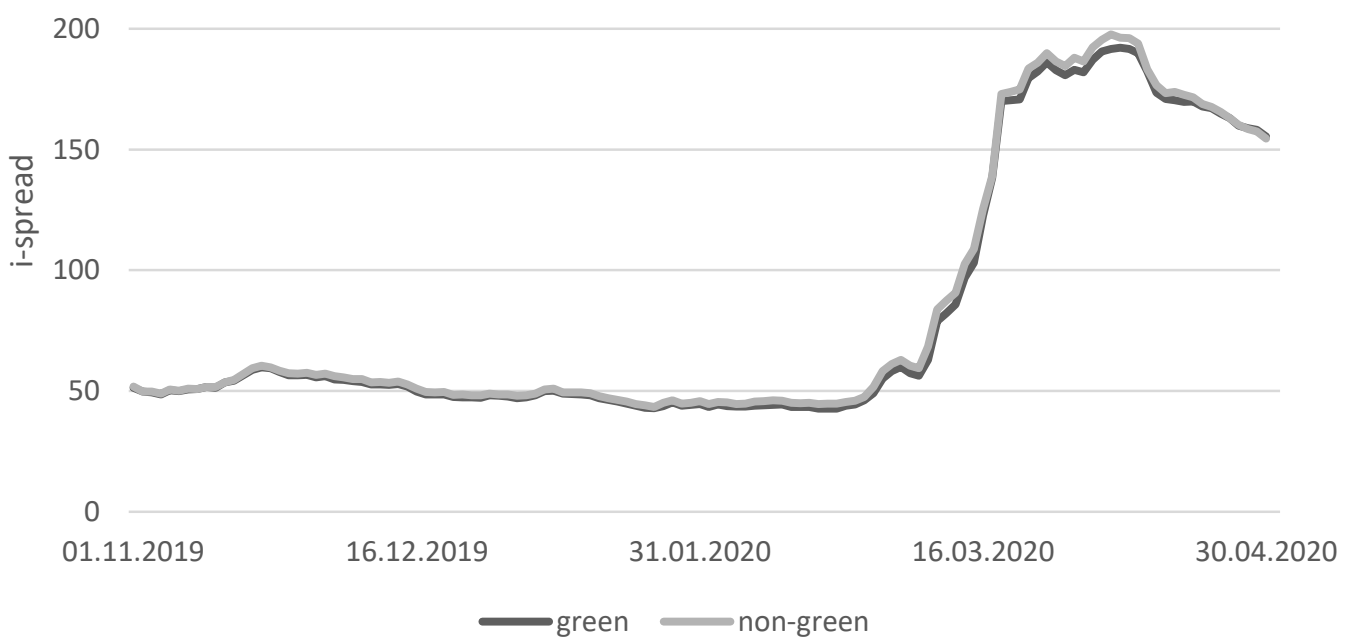


The BBB-rated bonds are the affected of all the rating classes with an increase of close to 150 bps p.a. (1.50\% yield). The cause of this is that the BBB rating is the last rating class of the investment grade type and investors are concerned about a possible downgrade to noninvestment grade rating (Hachenberg and Schiereck (2018)). Moreover, this rating category contains mostly corporate bonds, which were hit hardest by the crisis. From BBB- to AAArated bonds, the bond market movement is less volatile. For AAA-rated bonds, the difference in i-spreads is only slightly more than 15 bps p.a. (0.15\% yield). In short, the lower the default risk, the less the market movement affects yields.

\section{CONCLUSION}

Since the introduction of the first green bond in 2008, green bonds contribute to the fight against climate change by providing funds for sustainable projects to achieve the goals of the Paris Agreement. The international community's commitment to achieving the SDGs and other environmental targets is essential for the further development of green markets. The underlying analysis of green bond characteristics and financing conditions in Europe is of great importance for investors, bond issuers, policymakers and the public. Additionally, the yield performance of green compared to non-green bonds significantly influences how many new green bonds are issued and demanded. Countries can enact structured policies that promote the demand and supply of green securities making sustainability and risks a component of financial decisions.

Previous green bond studies that investigated the green bond premium presented mixed findings, however, there is a tendency toward observing a negative green bond premium. This study adds to the existing literature by investigating the green bond premium with the most recent data, especially for issuers incorporated in Europe. The results of the analysis suggest that there is an average negative green bond premium of 0.93 bps p.a. in the secondary European market, which, in economic terms, is very small. It means that an investor investing green would have to forgive $0.0093 \%$ in yield p.a. In the observation period between November 1, 2019, and April 30, 2020, lower-rated bonds do not show a significantly higher negative green bond premium. Only BBB-rated green bonds had a significantly larger negative green bond premium in comparison to the other three rating groups. It also becomes visible that investors demanded higher yields at the beginning of the Corona-Pandemic due to the increased default risk arising from the unknown economic consequences of the coronavirus crisis at the end of March 2020.

The negative green bond premium creates an incentive for institutions and corporations alike to issue green bonds because they can refinance themselves at a discount when compared to brown bonds. An economically small negative green bond premium also attracts investors. Thus, policymakers can substantially support sustainable development by further promoting green bond markets which hopefully leads to the achievement of the Paris Agreement's goals.

\section{REFERENCES}

Bachelet, M. J., Becchetti, L., \& Manfredonia, S. (2019). The Green Bonds Premium Puzzle: The Role of Issuer Characteristics and Third-Party Verification. Sustainability, 11(4), 1098.

Berensmann, K., \& Lindenberg, N. (2019). Green Finance: Across the Universe. In S. Boubaker \& D. K. Nguyen (Eds.), Corporate Social Responsibility, Ethics and Sustainable Prosperity (pp.305-332). WORLD SCIENTIFIC. https://doi.org/10.1142/9789811206887_0011 
Boracheva, O., \& Smorodinov, O. (2017). CHALLENGES TO GREEN FINANCE IN G20 COUNTRIES. World Economy and International Relations, 61(10), 16-24. https://doi.org/10.20542/0131-2227-2017-61-10-16-24

Bösch, M. (2020). Derivate: Verstehen, anwenden und bewerten (4. Auflage). München: Vahlen, Franz.

Boulle, B., Frandon-Martinet, C., \& Pitt-Watson, J. (2016). Bonds and Climate Change. The State of the Market in 2016. Climate Bonds Initiative.

CBI (2020). 2019 Green Bond Market Summary. Retrieved from https://www.climatebonds.net/files/reports/2019_annual_highlights-final.pdf [05.05.2020]

Ceci, M. (2016). Green, Social and Sustainability Bonds. J.P. Morgan.

Dorfleitner, G., Halbritter, G., \& Nguyen, M. (2015). Measuring the Level and Risk of Corporate Responsibility - An Empirical Comparison of Different ESG Rating Approaches. Journal of Asset Management, 16(7), 450-466. https://doi.org/10.1057/jam.2015.31

Ehlers, T., \& Packer, F. (2017). Green Bond Finance and Certification. Bank for International Settlements Quarterly Review. Retrieved from https://www.bis.org/publ/qtrpdf/r_qt1709h.pdf [15.05.2020]

Fleming, M. J., \& Remolona, E. M. (1999). What Moves Bond Prices? The Journal of Portfolio Management, 25(4), 28-38. https://doi.org/10.3905/jpm.1999.319756

G20 Green Finance Study Group (2016). G20 Green Finance Synthesis Report. Retrieved from http://unepinquiry.org/wp-content/uploads/2016/09/Synthesis_Report_Full_EN.pdf [10.05.2020]

Green Finance Initiative (2016). Globalising Green Finance: The UK as an International Hub. London: City of London Corporation.

Hachenberg, B., \& Schiereck, D. (2018). Are Green Bonds Priced Differently from Conventional Bonds? Journal of Asset Management, 19(6), 371-383. https://doi.org/10.1057/s41260-018-0088-5

Kahlenborn, W., Cochu, A., Georgiev, I., Eisinger, F., \& Hogg, D. (2017). Defining "Green" in the Context of Green Finance: Final Report. Brussels: European Commission.

Karpf, A., \& Mandel, A. (2018). The Changing Value of the 'Green' Label on the US Municipal Bond Market. Nature Climate Change. (8), 161-165. https://doi.org/10.1038/s41558017-0062

Ketterer, J. A., Andrade, G., Netto, M., Haro, \& Isabel, M. (2019). Transforming Green Bond Markets: Using Financial Innovation and Technology to Expand Green Bond Issuance in Latin America and the Caribbean: Inter-American Development Bank.

Migliorelli, M., \& Dessertine, P. (Eds.) (2020). Palgrave Studies in Impact Finance. The Rise of Green Finance in Europe: Opportunities and Challenges for Issuers, Investors and Marketplaces. Basingstoke: Palgrave Macmillan.

OECD (2018). Financing Climate Futures: Rethinking Infrastructures. Retrieved from https://www.oecd.org/environment/cc/climate-futures/policy-highlights-financingclimate-futures.pdf [01.06.2020]

Polbennikov, S., Desclée, A., Dynkin, L., \& Maitra, A. (2016). ESG Ratings and Performance of Corporate Bonds. The Journal of Fixed Income, 26(1), 21-41. https://doi.org/10.3905/jfi.2016.26.1.021

Preclaw, R., \& Bakshi, A. (2015). The Cost of Being Green. Barclays Credit Research. Retrieved from https://www.environmentalfinance.com/assets/files/US_Credit_Focus_The_Cost_of_Being_Green.pdf [01.06.2020] 
Der Tagesspiegel (2020). Was die fallenden Kurse sämtlicher Anleihen für Anleger bedeuten, 18.03.2020. Retrieved from https://www.tagesspiegel.de/verbraucher/coronavirus-wasdie-fallenden-kurse-saemtlicher-anleihen-fuer-anleger-bedeuten/25657358.html [20.04.2020]

Zerbib, O. D. (2019). The Effect of Pro-Environmental Preferences on Bond Prices: Evidence from Green Bonds. Journal of Banking and Finance, 2019(98), 39-60.

https://dx.doi.org/10.2139/ssrn.2889690 